\title{
CORRESPONDENCE
}

\section{Arizona's big city lights are damaging astronomy}

SIR - As Malcolm Smith points out in his Commentary 'Time to turn off the lights' (Nature 457, 27; 2009), significant economic benefits are to be had in the form of reduced electricity bills once efficient, astronomy-friendly outdoor lighting is adopted.

In locations such as Arizona, Hawaii and Chile, which are particularly suited to groundbased observational astronomy, the failure of governments to enact and enforce appropriate light-pollution controls could eventually lead to great economic losses. A study conducted by the University of Arizona's Eller College of Management, and sponsored by the Arizona Arts, Sciences and Technology Academy, showed that in financial year 2005-06 the total economic impact in Arizona of astronomical and space-science research was over US $\$ 250$ million. More than 3,300 jobs were supported directly or indirectly by the flow of these dollars into the state (www. aasta.net). Although I am not aware of comparable studies of the economic impact of astronomy and space science in Hawaii and Chile, it is evidently significant.

Cities in Arizona, such as Flagstaff and Tucson, and the surrounding Coconino and Pima counties, long ago enacted lighting ordinances designed to protect the nearby observatories, and these are enforced. However, our dark skies continue to be degraded by light pollution originating from more distant, larger and rapidly growing regions, such as the greater Phoenix metropolitan area and Pinal County between Phoenix and Tucson, where lighting ordinances are typically less stringent. Unless better lighting controls are enacted in these areas, the competitiveness of Arizona's observatories will be harmed and the state, instead of benefiting from further growth of this clean and green enterprise, could experience a serious decline in astronomy's contribution to the state's economy.

I do not know whether observatories in Hawaii and Chile are vulnerable to a threat of similar magnitude, but I very much doubt they are immune.

Robert L. Millis Lowell Observatory, 1400 West Mars Hill Road, Flagstaff, Arizona 86001, USA

e-mail: rlm@lowell.edu

\section{It should be possible to replace animals in research}

\section{SIR - In his Correspondence}

'Replacement of animals in research will never be possible' (Nature 457, 147; 2009), Roberto Caminiti makes a case for retaining the current breadth of medical research in using non-human primates. Although immense progress has been made from scientifically well-founded work on non-human primates, I cannot agree with his contention that it will never be possible to replace these animals in research.

To my mind, there is a moral inconsistency attached to studies of higher brain function in non-human primates: namely, the stronger the evidence that non-human primates provide excellent experimental models of human cognition, the stronger the moral case against using them for invasive medical experiments. From this perspective, 'replacement' should be embraced as a future goal.

We should not assume that good medical science is by definition morally justifiable or morally acceptable. The European Union proposal that sparked Caminiti's Correspondence is rekindling this morally and scientifically essential debate.

Bill Crum Centre for Neuroimaging Sciences, Institute of Psychiatry, King's College London, De Crespigny Park, London SE5 8AF, UK e-mail:bill.crum@iop.kcl.ac.uk

\section{Guarding Hubble telescope's future for posterity}

SIR - In her Review '18 years of science with the Hubble Space Telescope' (Nature 457, 41-50, 2009), Julianne Dalcanton discusses the telescope's remarkable achievements. I am saddened at the thought that the best end for Hubble that NASA can devise is simply to burn it up.

Although the coming repair mission may be the last from NASA, it need not be the last mission to Hubble, which will still have use as a scientific instrument. Perhaps another nation might want to adopt it? As humankind progresses farther into space, a saved Hubble would be a treasured artefact.

What is necessary right now is that NASA should use this last mission to secure attachment points to Hubble so that a future, unmanned satellite could dock and raise it to a secure orbit.

Paul L. Schwartz, East Hampton, New York 11937, USA e-mail: plschwartz@hotmail.com

\section{Benefits of stemming bovine TB need to be demonstrated}

SIR - In their replies to our Correspondence on bovine tuberculosis (TB) 'Does risk to humans justify high cost of fighting bovine TB?' (Nature 455, 1029; 2008), Noel Smith and Richard Clifton-Hadley ('Bovine TB: don't get rid of the cat because the mice have gone') and Stephen Gordon ('Bovine TB: stopping disease control would block all live exports') argue that these costs are indeed warranted (Nature 456, 700; 2008).

The current surveillance system for bovine TB may remove cattle at an early stage of infection, as Smith and Clifton-Hadley suggest, but the UK cattle herd is generally young and bovine TB is a chronic disease. Hence, in the absence of control, very few cattle would be likely to reach the advanced stage of the disease at which airborne transmission might, at least in theory, be increased. It is also worth noting that in the early twentieth century, before bovine-TB control was instigated, almost all cases of zoonotic TB in the United Kingdom were non-pulmonary, and most of the small number of pulmonary cases seemed to come from haematogenous spread rather than airborne infections (A. S. Griffith Tubercle 18, 528-543; 1937). With larger farming enterprises and fewer farmers, the at-risk population would be a fraction of that prevailing previously. Human exposure would therefore be likely to remain very low, even in the absence of bovine-TB control.

Gordon claims that abandoning bovine-TB control would bring all live exports to a stop, and he compares Britain's bovine-TB programme to that put in place for foot-and-mouth control in 2001. But foot-and-mouth disease has a devastating economic effect on livestock that goes beyond merely closing down exports, and the cost of the 2001 UK outbreak was a one-off, non-recurring charge. Bovine-TB control is costing up to $€ 99$ million (US\$140 million) a year and, according to Gordon's own data, live exports have a value that is considerably less.

In addition, the ongoing bovineTB programme in the United Kingdom is failing to eliminate the disease. Those who propose to spend large amounts of public money on bovine-TB control need to demonstrate the economic and/or public-health benefit; so far, such evidence has been lacking.

Paul Torgerson Ross University School of Veterinary Medicine, PO Box 334, Basseterre, St Kitts, West Indies e-mail: ptorgerson@rossvet.edu.kn David Torgerson Department of Health Sciences, University of York, York YO10 5DD, UK

Contributions may be submitted tocorrespondence@nature.com. 